\title{
Endoscopic retrieval of a lumen-apposing metal stent complicated by inward migration after cystogastrostomy
}

Endoscopic ultrasound (EUS)-guided drainage is well known as an established technique for the treatment of pancreatic pseudocysts [1,2]. New covered metal stents, known as lumen-apposing metal stents (LAMS), have been designed. Despite their superior antimigration features, these LAMS can migrate inwardly

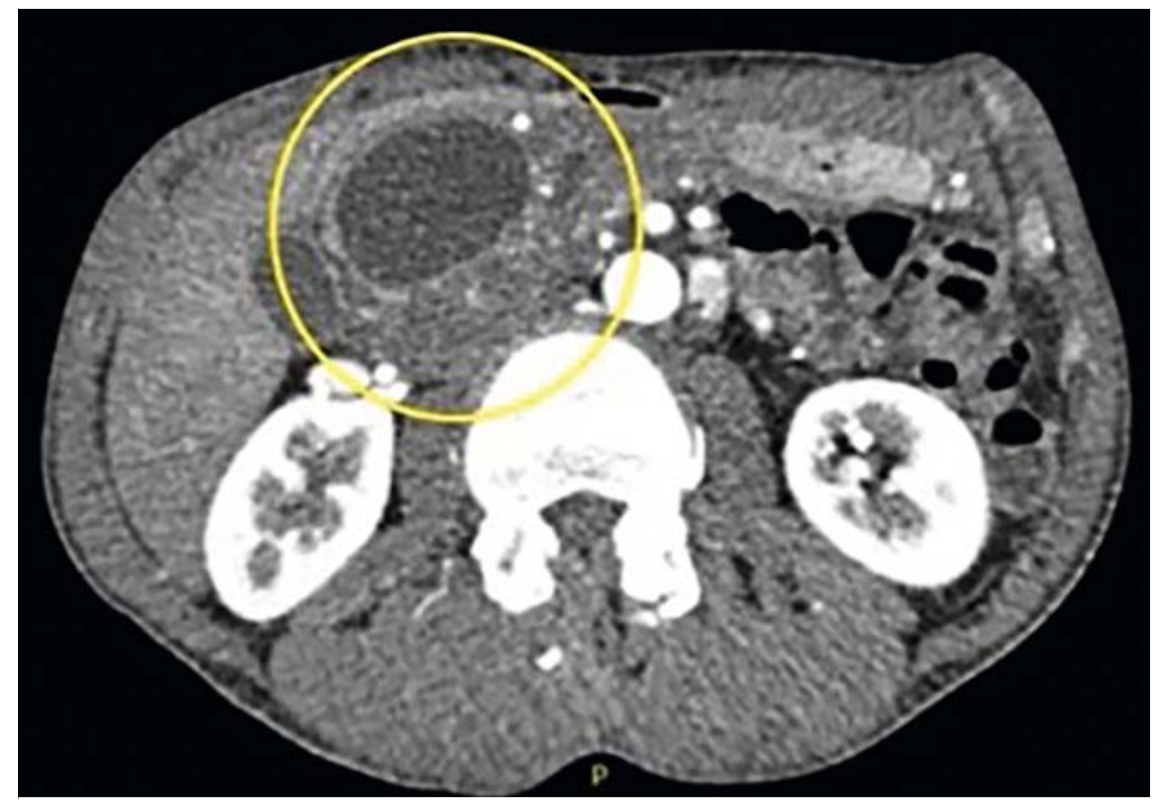

- Fig. 1 Computed tomography scan demonstrating a large pancreatic pseudocyst (circled) at the head of the pancreas, requiring endoscopic ultrasound-guided drainage.
$[3,4]$. We report a case of successful endoscopic retrieval of a LAMS with inward migration after cystogastrostomy.

A 50-year-old man with a history of alcohol-induced chronic pancreatitis complicated by a large pancreatic pseudocysts at the head of the pancreas (-Fig.1), presented with severe abdominal pain and gastric outlet obstruction. EUS-guided cystogastrostomy was successfully performed with a 15-mm LAMS (> Fig. 2). The patient returned for stent removal 2 months later, and the follow-up computed tomography (CT) scan revealed resolution of the cyst. However, during the esophagogastroduodenoscopy to remove the stent, we observed a small orifice at the location of the previously applied stent ( $\mathbf{F i g} \cdot \mathbf{3 a}$ ). Fluoroscopic images confirmed stent migration into the fistulous lumen of the remaining pseudocyst ( $\mathbf{F i g} \mathbf{3} \mathbf{b}$ ). We proceeded with endoscopic retrieval of LAMS ( $\triangleright$ Video 1 ).

The retrieval procedure was performed under general anesthesia. Carbon diox-
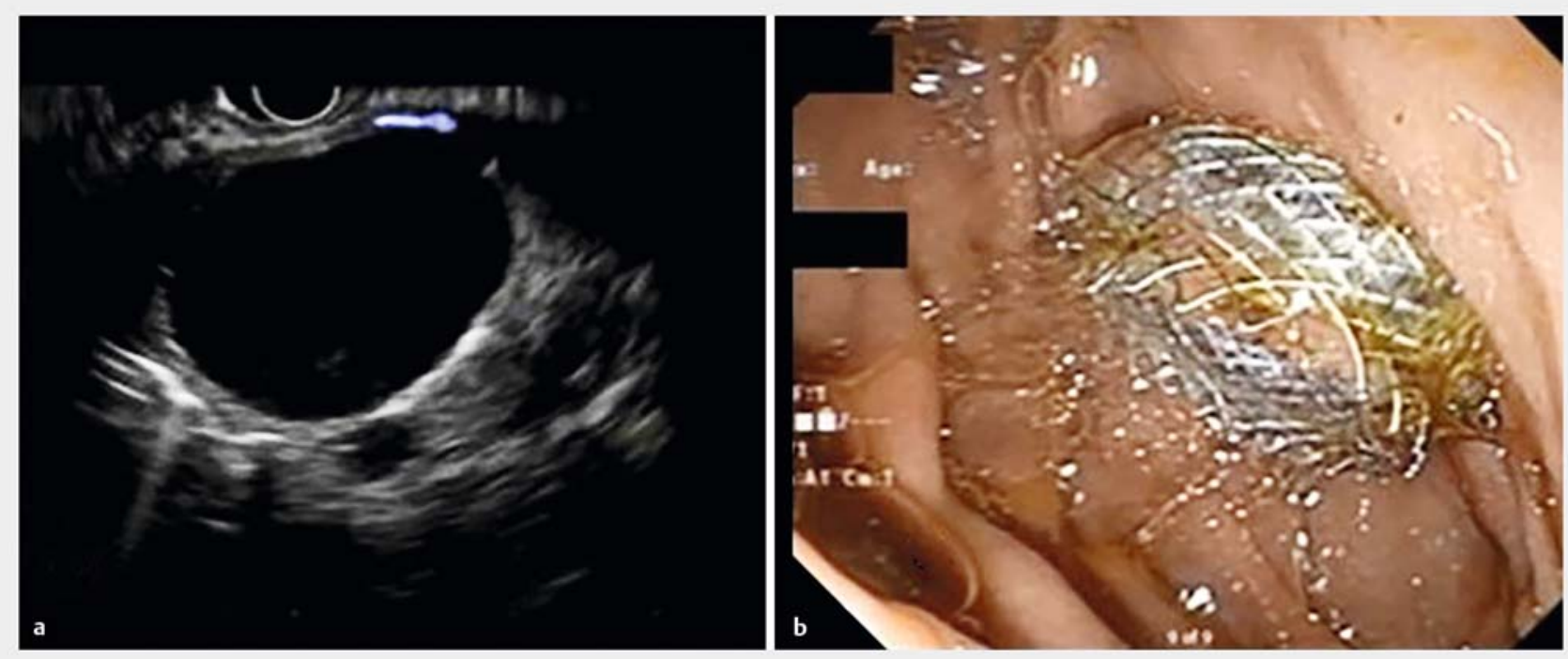

Fig. 2 Treatment of the pseudocyst. a Endoscopic ultrasound (EUS) image of the cystogastrostomy. b Endoscopic image of successful EUSguided drainage of the pseudocyst with a lumen-apposing metal stent. 

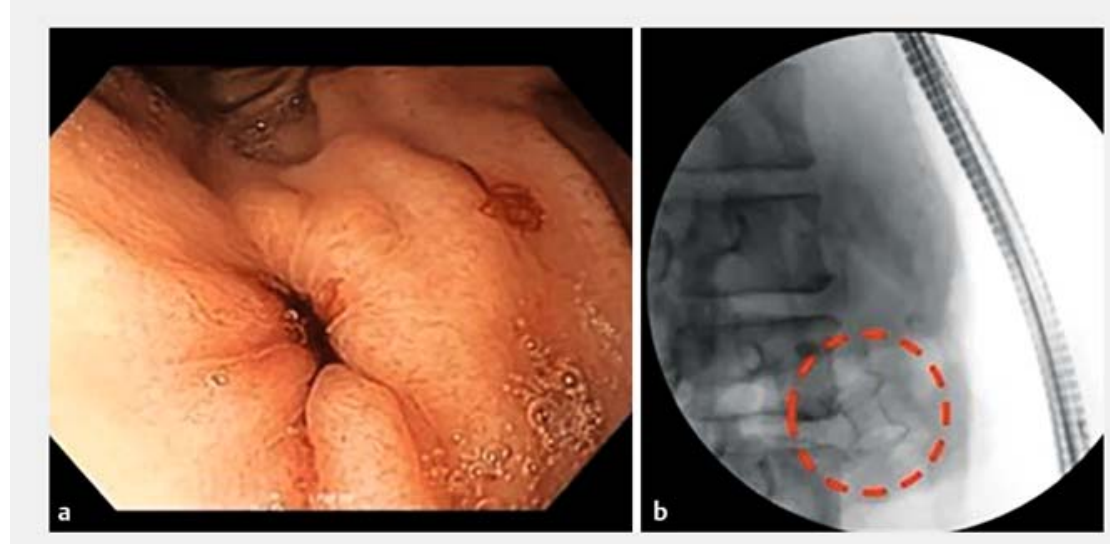

- Fig. 3 Stent removal. a Endoscopic image of orifice at location of previously applied stent. b Fluoroscopic image confirming stent migration into the lumen of the remaining pseudocyst.

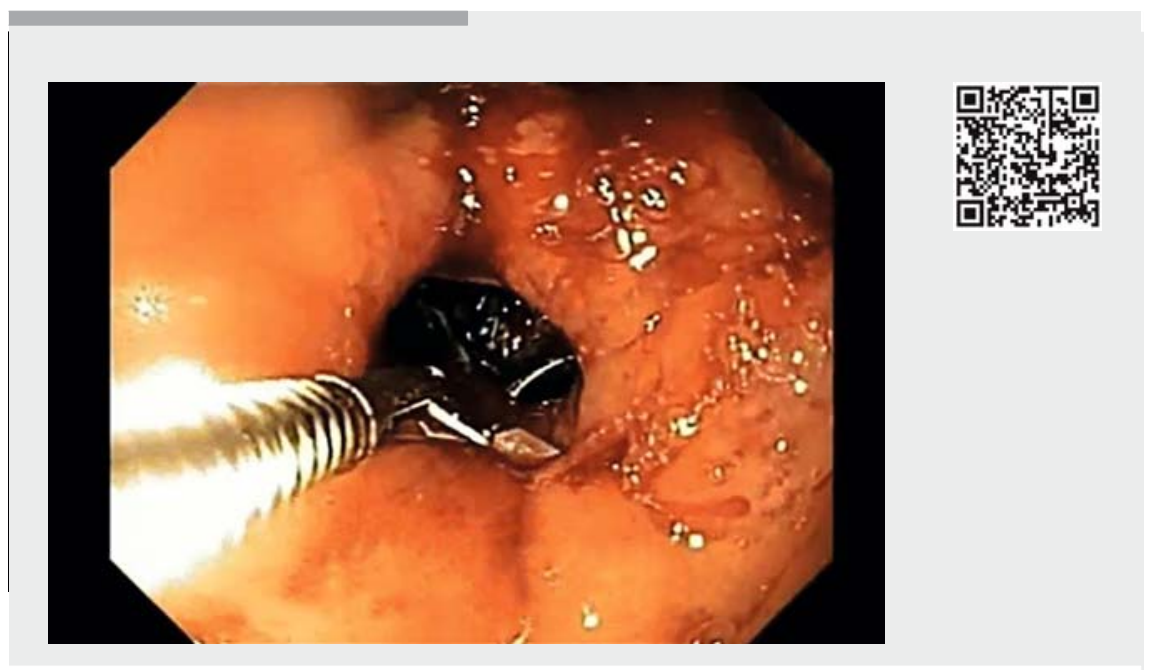

Video 1 Endoscopic retrieval of an inwardly migrated lumen-apposing metal stent after cystogastrostomy.

ide was used for this procedure. A long 0.035-inch guidewire was passed under fluoroscopic guidance through the fistulous tract. After serial dilations to $15 \mathrm{~mm}$, under fluoroscopic guidance, the LAMS was successfully retrieved from the dilated orifice using rat-tooth forceps ( Fig.4). An over-the-scope clip was deployed to close the gastric opening. Post-procedurally, the patient had mild abdominal pain, which was managed conservatively. Post-procedure CT scan showed complete closure of the cystogastrostomy and ruled out perforation. In conclusion, despite superior antimigration features of new LAMS, inward migration has been reported. Successful retrieval of LAMS complicated by inward migration can be safely achieved by endoscopic means under fluoroscopic guidance.

Endoscopy_UCTN_Code_CPL_1AL_2AD

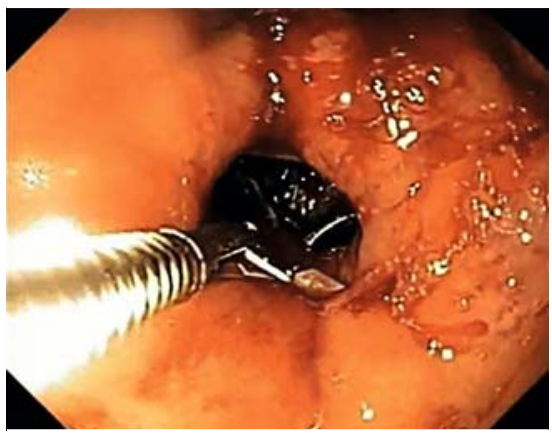

- Fig. 4 Retrieval of a lumen-apposing metal stent from the lumen of the remaining pseudocyst, using a rat-tooth forceps.

Competing interests

None

The authors

Neal Mehta', Ashraf Abushahin', Matheus Franco $^{2}$, Tyler Stevens ${ }^{2}$, Prabhleen Chahal ${ }^{2}$, John Vargo ${ }^{2}$, Amit Bhatt ${ }^{2}$

1 Department of Internal Medicine, Medicine Institute, Cleveland Clinic Foundation, Cleveland, Ohio, United States

2 Department of Gastroenterology and Hepatology, Digestive Disease and Surgery Institute, Cleveland Clinic Foundation, Cleveland, Ohio, United States

\section{Corresponding author}

\section{Amit Bhatt, MD}

Department of Gastroenterology and Hepatology, Desk A-30, Cleveland Clinic Foundation, 9500 Euclid Avenue, Cleveland, $\mathrm{OH}, 44195$, United States

Fax: +1-216-445-6290

bhatta3@ccf.org 


\section{References}

[1] Varadarajulu S, Christein JD, Tamhane A et al. Prospective randomized trial comparing EUS and EGD for transmural drainage of pancreatic pseudocysts (with videos). Gastrointest Endosc 2008; 68: 1102 - 1111

[2] Chak A. Endosonographic-guided therapy of pancreatic pseudocysts. Gastrointest Endosc 2000; 52 (Suppl. 06): S23 - S27

[3] Yamamoto N, Isayama H, Kawakami $\mathrm{H}$ et al. Preliminary report on a new, fully covered, metal stent designed for the treatment of pancreatic fluid collections. Gastrointest Endosc 2013; 77: 809-814
[4] DeSimone ML, Asombang AW, Berzin TM. Lumen apposing metal stents for pancreatic fluid collections: recognition and management of complications. World J Gastrointest Endosc 2017; 9: 456 - 463

Bibliography

DOI https://doi.org/10.1055/a-0640-2786

Published online: 8.8.2018

Endoscopy 2018; 50: E286-E288

(c) Georg Thieme Verlag KG

Stuttgart · New York

ISSN 0013-726X

\section{ENDOSCOPY E-VIDEOS}

https:/|eref.thieme.de/e-videos

回局 Endoscopy E-Videos is a free access online section, reporting 回: on interesting cases and new techniques in gastroenterological endoscopy. All papers include a high quality video and all contributions are freely accessible online.

This section has its own submission website at

https://mc.manuscriptcentral.com/e-videos 